\title{
Modification of seed oil composition in Arabidopsis by artificial microRNA-mediated gene silencing
}

\author{
Srinivas Belide ${ }^{1,2+}$, James Robertson Petrie ${ }^{1 \dagger}$, Pushkar Shrestha ${ }^{1}$ and Surinder Pal Singh ${ }^{1}$ * \\ ' Food Futures National Research Flagship, CSIRO Plant Industry, Canberra, ACT, Australia \\ 2 Department of Biotechnology, Sreenidhi Institute of Science and Technology, Hyderabad, Andhra Pradesh, India
}

Edited by:

Vincent Bulone, Royal Institute of Technology, Sweden

Reviewed by:

Chen Hongzhang, Chinese Academy of Sciences, China

Gijs A. Kleter, RIKILT - Institute of

Food Safety, Netherlands

\section{*Correspondence:}

Surinder Pal Singh, Food Futures

National Research Flagship, CSIRO

Plant Industry, P.O. Box 1600,

Canberra, ACT 2601, Australia.

e-mail: surinder.singh@csiro.au

${ }^{\dagger}$ Srinivas Belide and James Robertson Petrie have contributed equally to this work.
Various post transcriptional gene silencing strategies have been developed and exploited to study gene function or engineer disease resistance. The recently developed artificial microRNA strategy is an alternative method of effectively silencing target genes. The $\triangle 12$-desaturase (FAD2), Fatty acid elongase (FAE1), and Fatty acyl-ACP thioesterase B (FATB) were targeted with amiR159b-based constructs in Arabidopsis thaliana to evaluate changes in oil composition when expressed with the seed-specific Brassica napus truncated napin (FP1) promoter. Fatty acid profiles from transgenic homozygous seeds reveal that the targeted genes were silenced. The down-regulation of the AtFAD-2 gene substantially increased oleic acid from the normal levels of $\sim 15 \%$ to as high as 63.3 and reduced total PUFA content $\left(18: 2^{\Delta 9,12}+18: 3^{\Delta 9,12,15}+20: 2^{\Delta 11,14}+20: 3^{\Delta 11,14,17}\right)$ from 46.8 to $4.8 \% . \Delta 12$-desaturase activity was reduced to levels as low as those in the null fad-2-1 and fad-2-2 mutants. Silencing of the FAE1 gene resulted in the reduction of eicosenoic acid $\left(20: 1^{\Delta 11}\right)$ to 1.9 from $15.4 \%$ and silencing of FATB resulted in the reduction of palmitic acid $(16: 0)$ to $4.4 \%$ from $8.0 \%$. Reduction in FATB activity is comparable with a FATB knock-out mutant. These results demonstrate for the first time amiR159b constructs targeted against three endogenous seed-expressed genes are clearly able to down-regulate and generate genotypic changes that are inherited stably over three generations.

Keywords: miR159b, fatty acid desaturase 2, fatty acid elongase, fatty acyl-ACP thioesterase B, fatty acid profiles

\section{INTRODUCTION}

MicroRNAs (miRNAs) are a class of 20-24-nucleotide (nt) regulatory small RNAs (sRNA) endogenous to both plants and animals which represent a recently developed miRNA-based strategy to silence endogenous genes. It has been demonstrated that the alteration of several nucleotides within the miRNA sequence does not affect its biogenesis as long as the positions of matches and mismatches within the precursor stem loop remain unaffected (Herve et al., 2004). This raises the possibility of modifying miRNA sequences and creating artificial miRNAs (amiRNA) directed against any gene of interest resulting in posttranscriptional silencing of the corresponding transcript. The amiRNA technology was first used for gene knock down in human cell lines, and it was successfully employed to down-regulate gene expression without affecting the expression of other unrelated genes in transgenic plants (Schwab et al., 2006; Warthmann et al., 2008). Since its successful application in silencing endogenous genes in plants several amiRNA vectors viz. ath-miR159a, athmiR164b, ath-miR172a, ath-miR319a, and osa-miR528 recently been developed and tested.

Artificial microRNA based gene silencing is becoming a powerful tool and now commonly used in plant genetic engineering and under certain circumstances, can offer advantages over traditional

Abbreviations: FAD2, fatty acid desaturase 2; FAE1, fatty acid elongase; FATB, fatty acyl-ACP thioesterase B, ODP, oleic desaturation proportion; OEP, oleic elongation proportion. hairpin-based RNA interference (RNAi). Foremost among these is the ability to silence specific transcripts amongst gene families with a reduced risk of cross-silencing and, because of this, amiRNA has been described as a second-generation RNAi technology (Tang et al., 2007). There are numerous examples of the use of amiRNA to down-regulate endogenous plant genes (Alvarez et al., 2006; Khraiwesh et al., 2008; Molnar et al., 2009) and also for developing transgenic virus resistance (Niu et al., 2006; Qu et al., 2007; Duan et al., 2008; Zhang et al., 2010; Ai et al., 2011). amiRNA has also been widely used for gene function studies and has moved rapidly from model plants to crop species (Gaurav et al., 2011), for instance in elucidating the function of FLOT4 and FLOT2 in nitrogen fixation in Medicago truncatula (Haney and Long, 2010). Male sterility has been achieved by targeting TBPassociated factors which plays crucial role in many developmental aspects including pollen development in the egg plant (Toppino et al., 2011).

Naturally occurring mutations in genes encoding fatty acid metabolizing enzymes provide a resource for novel oilseed phenotypes, but the effects of such changes are evident in all tissues and organs of the plant (Somerville and Browse, 1991). In contrast, transgenic gene suppression techniques in conjunction with seedspecific promoters has been used as a way to restrict the effects of targeted gene suppression to oil accumulating tissues within seeds (Pidkowich et al., 2007). Many attempts have been made to improve the fatty acid composition of plant oils through the seedspecific expression of various heterologous biosynthetic activities, 
with varying degrees of success (Napier, 2007) and tissue specific gene silencing is going play a major role in tailoring plant lipid composition. High oleic oils have real opportunity to substitute existing products used in high stability applications due to functional, health, and sensory benefits. Monounsaturates have higher rates of oxidative stability and consequently, have lower formation rates of oxidation products. In addition to food uses, high oleic oils have industrial applications (cosmetic, lubricant, transmission, and hydraulic) with possible ecological benefits through replacement of mineral oil. Also, saturated fatty acids such as palmitic acid (16:0) have been suggested to play a role in raising LDL cholesterol so oils that are engineered to be low in palmitic acid and rich in oleic acid could offer health benefits.

Several approaches, including antisense (Sellwood et al., 2000), co-suppression (Jadhav et al., 2005) and RNAi (Surinder et al., 2000), combined antisense-hairpin RNA (Tam and John, 2009) have been used to silence the gene expression related to oil synthesis in seed tissues. Importantly, there are examples of genetically modified soybean events with RNAi constructs that target FAD2 and/or Fatty acyl-ACP thioesterase B (FATB) genes for increased oleic acid accumulation that are being deregulated in several countries (e.g., 305423 and MON87705 high oleic soybeans). However microRNA based gene silencing has been not reported in model plants or other economically important oil seed crops for modulating the gene expression related to oil synthesis. In this paper we report for the first time the use of amiRNA based gene silencing of three important genes, i.e., Fatty acid desaturase 2 (FAD2), Fatty acid elongase (FAE1), and FATB involved in seed oil metabolism.

\section{MATERIALS AND METHODS CONSTRUCTION OF THREE ARTIFICIAL A. THALIANA MIR159B GENES FOR SEED-SPECIFIC PLANT EXPRESSION}

A seed-specific expression binary vector, pJP1105 (GenBank accession JX155386), was constructed by cloning a modified version of the Arabidopsis thaliana miR159b gene from pBlueGreen (kindly supplied by Dr. Peter Waterhouse; Eamens et al., 2009) into the SpeI-XhoI sites of a vector, FP1-pORE03. This vector was constructed by cloning a truncated napin promoter (FP1) into binary vector pORE03 (Coutu et al., 2007). The CSIRO software package MatchPoint (http://www.pi.csiro.au/RNAi; Horn and Waterhouse, 2010) was used to identify three 21 mer sequences which would target $A$. thaliana FAD2, FAE1, and FATB, respectively, without affecting off-target genes (Table 1). Three seed-specific expression versions of artificial $A$. thaliana ara-miR159b genes were generated by cloning modified stem loop regions into pJP1105 at the $L g u \mathrm{I}$ sites to generate pJP1106, pJP1109, and pJP1110 (Figure 1). The genes targeted in these experiments were all fatty acid synthesis genes and were chosen since the phenotypes of lines in which they were silenced were quantifiable. FAD2 silencing results in increased $18: 1^{\Delta 9}$, the substrate of the FAD2 enzyme. FAE1 silencing is most easily discerned by a decrease in the level of the product fatty acid, 20:1 ${ }^{\Delta 11}$ whilst FATB silencing is most noticeable as a decrease in 16:0 which is exported to a lesser degree from the plastid to the cytosol (Figure 2).

\section{ARABIDOPSIS PLANT TRANSFORMATION}

pJP1106, pJP1109, and pJP1110 was transformed into separate Agrobacterium tumefaciens strain AGL1 by electroporation and the transformed strains used to introduce the genetic construct into A. thaliana (ecotype Columbia). Plant transformation was carried out using the floral dipping method (Clough and Bent, 1998). All transgenic plants were grown in a greenhouse under natural day length with a controlled temperature of $24^{\circ} \mathrm{C}$ in the daylight hours and $18^{\circ} \mathrm{C}$ in the evening, while Columbia wild type

\begin{tabular}{|c|c|}
\hline Name & Oligonucleotide sequence \\
\hline FAD2-F & $\begin{array}{l}\text { TATATGCTCTTCGAGAGGGGCCTCGATGAGATGCCTCTTGGA } \\
\text { GGGTTTAGCAGGGTGAAGTAAAG }\end{array}$ \\
\hline FAD2-R & $\begin{array}{l}\text { TATATGCTCTTCGAGATGGGCCTCGATGATCTGCCTCTAGAAG } \\
\text { AGTGAAGCCATTAAAGGG }\end{array}$ \\
\hline FAE1-F & $\begin{array}{l}\text { TATATGCTCTTCGAGAGGACCGGAGACGGGACAAGTACTGGA } \\
\text { GGGTTTAGCAGGGTGAAGTAAAG }\end{array}$ \\
\hline FAE1-R & $\begin{array}{l}\text { TATATGCTCTTCGAGATGACCGGAGACGGTCCAAGTACAGAAG } \\
\text { AGTGAAGCCATTAAAGGG }\end{array}$ \\
\hline FATB-F & $\begin{array}{l}\text { TATATGCTCTTCGAGAGGACCTGGGTCAGGAAGTCTGGTGGA } \\
\text { GGGTTTAGCAGGGTGAAGTAAAG }\end{array}$ \\
\hline FATB-R & $\begin{array}{l}\text { TATATGCTCTTCGAGATGACCTGGGTCAGTCAGTCTGGAGAAG } \\
\text { AGTGAAGCCATTAAAGGG }\end{array}$ \\
\hline
\end{tabular}

The 21 mer regions targeting the Arabidopsis thaliana genes are underlined.

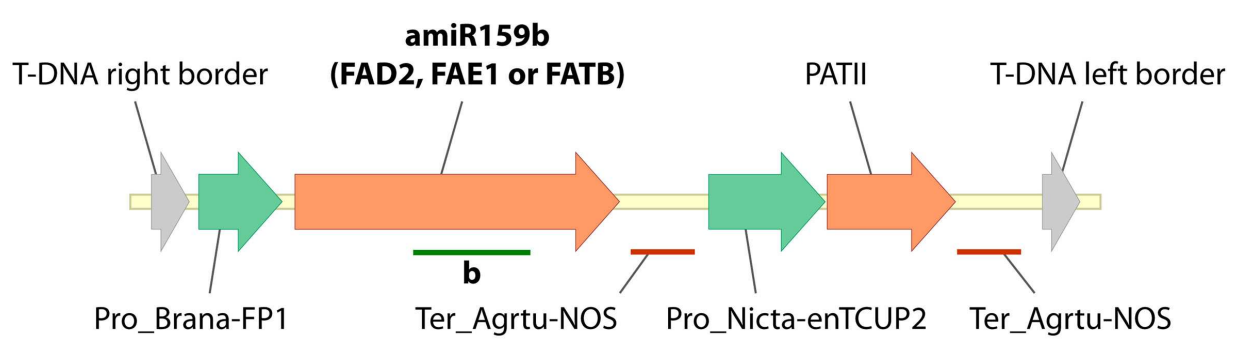

$1 \mathbf{~ k b}$

FIGURE 1 | Construct maps (T-DNA border-border regions only) the single-gene miR159b-based pJP1106, pJP1109, and pJP1110 which differ only in the $\mathbf{2 1 m e r}$ sequences in the stem loops. Stem loops are shown as green bars under the amiRNA genes. 


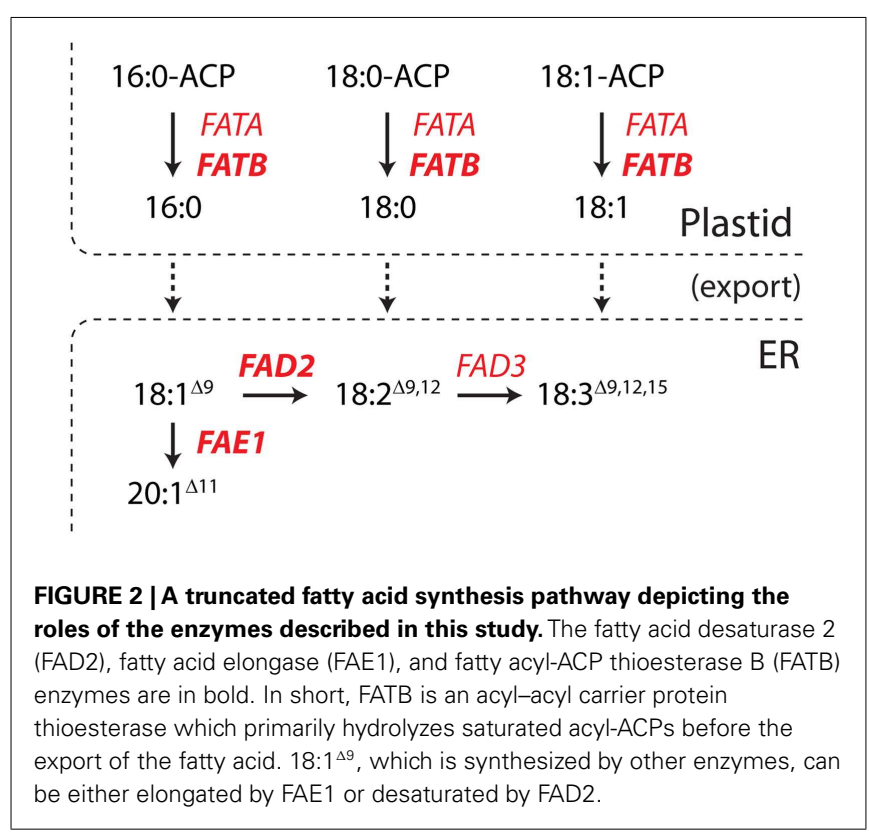

and hpRNA FAD2 silenced line (3-1-1; Stoutjesdijk et al., 2002) were grown alongside to compare the efficiency of silencing. Sterilized seeds ( $\mathrm{T}_{1}$ seeds) from the transformed plants ( $\mathrm{T}_{0}$ plants) were plated out on MS media (Murashige and Skoog, 1962) supplemented with $3.5 \mathrm{mg} / \mathrm{L}$ PPT and incubated at $24 \pm 1{ }^{\circ} \mathrm{C}$ under 16 photoperiod with the light intensity of $200 \mu \mathrm{mol} / \mathrm{m}^{2} / \mathrm{s}$ for 3 weeks. Surviving seedlings were subjected to another round of PPT selection with similar conditions for another 2 weeks and $\sim 30$ PPT-resistant plants for each construct were isolated and transferred to soil to establish $\mathrm{T}_{1}$ transgenic plants. Most of these $\mathrm{T}_{1}$ plants were expected to be heterozygous for the introduced genetic construct. $\mathrm{T}_{2}$ seed from the transgenic $\mathrm{T}_{1}$ plants (selfed) were collected at maturity and analyzed for fatty acid composition. Lines displaying an apparent high level of FAD2 silencing were again germinated on PPT media and seedlings from lines with a 3:1 surviving:susceptible seedling ratio were transferred to soil. These lines were likely to contain single locus insertions and be either heterozygous or homozygous for the transgenic insert as null lines were selected against.

\section{FATTY ACID ANALYSIS}

Fatty acid methyl esters (FAME) were formed by transesterification of triplicate samples of $\sim 200$ seeds each by heating with $\mathrm{MeOH}-\mathrm{CHCl}_{3}-\mathrm{HCl}(10: 1: 1, \mathrm{v} / \mathrm{v} / \mathrm{v})$ at $90-100^{\circ} \mathrm{C}$ for $2 \mathrm{~h}$ in a glass test tube fitted with a Teflon-lined screw-cap. FAME were extracted into hexane:dichloromethane $(4: 1, \mathrm{v} / \mathrm{v})$ and analyzed by GC. GC was performed as described by Zhou et al. (2006) but using a BPX 70 polar column (SGE, Ringwood, VIC, Australia). Relative fatty acid compositions were calculated as the percentage that each fatty acid represented of the total fatty acid profile. Alterations to the activity of the $\Delta 12$-desaturase caused by the action of introduced transgenes could be seen as changes in the amounts of oleic acid and in the seed oil profiles. An additional indirect method of assessing the cumulative effects of $\Delta 12$-desaturase activity during seed fatty acid synthesis is through the oleic desaturation proportion (ODP) parameter, derived by the following formula:

$\mathrm{ODP}=\frac{\% 18: 2+\% 18: 3}{\% 18: 1+\% 18: 2+\% 18: 3}$

Oleic desaturation proportion represents the ratio of the total fatty acids accounting for the products of $18: 1^{\Delta 9}$ desaturation (i.e., $18: 2^{\Delta 9,12}$ and $18: 3^{\Delta 9,12,15)}$ to the total amount of $18: 1^{\Delta 9}$ substrate that was available, i.e., these products of $18: 1^{\Delta 9}$ modification plus the remaining $18: 1^{\Delta 9}$. Arabidopsis (ecotype Columbia) typically has an ODP value of around $0.70-0.79$, indicating that around 70 $79 \%$ of $18: 1^{\Delta 9}$ formed during fatty acid synthesis is subsequently converted to the polyunsaturated $\mathrm{C} 18$ fatty acids initially via the action of $\Delta 12$-desaturase. This parameter is useful in illustrating the effects of FAD2 gene silencing on the level of endogenous $\Delta 12$-desaturase activity.

Similarly, oleic elongation proportion (OEP) represents the ratio of the total fatty acids accounting for the products of $18: 1^{\Delta 9}$ elongation (i.e., $20: 1^{\Delta 11}$ and $22: 1^{\Delta 13}$ ) to the total amount of $18: 1^{\Delta 9}$ substrate that was available, i.e., the products of $18: 1^{\Delta 9}$ modification $\left(18: 2^{\Delta 9,12}\right.$ and $\left.18: 3^{\Delta 9,12,15}\right)$ plus the remaining $18: 1^{\Delta 9}$. Arabidopsis typically has an OEP value of around 0.20 0.22 , indicating that around $20-22 \%$ of $18: 1^{\Delta 9}$ formed during fatty acid synthesis is subsequently elongated via the action of FAE1. This parameter is useful in illustrating the effects of FAE1 gene silencing on the level of endogenous FAE1 activity.

$$
\mathrm{OEP}=\frac{\% 20: 1+\% 22: 1}{\% 18: 1+\% 18: 2+\% 18: 3+\% 20: 1+\% 22: 1}
$$

\section{STATISTICAL ANALYSIS}

Quantitative data, fatty acid profiles from homozygous seeds $\left(\mathrm{T}_{3}\right.$ and $\mathrm{T}_{4}$ ) were analyzed by One Way Analysis of Variance (ANOVA) using Sigmaplot (v12) by the Holm-Sidak method (Zar, 2010). Differences were considered significant at the $5 \%$ level.

\section{RESULTS AND DISCUSSION \\ EFFECT OF GENE SILENCING ON $\Delta 12$ DESATURATION LEVELS IN T 2 AND $T_{3}$ SEED}

FAD2 encodes an endoplasmic reticulum-localized $\Delta 12$ desaturase required for converting the monounsaturated oleic acid $\left(18: 1^{\Delta 9}\right)$ to the polyunsaturated linoleic acid $\left(18: 2^{\Delta 9,12}\right.$; Okuley et al., 1994). FAD2 is a classic reporter for silencing assays because it is a single-copy, non-essential gene in Arabidopsis and easily quantifiable (Miquel and Browse, 1992). $\Delta 12$-Desaturase is highly active in developing seeds of non-transgenic Arabidopsis (Columbia) and $18: 1^{\Delta 9}$ is $12.9 \pm 0.1$ (Table 2). Levels of $18: 1^{\Delta 9}$ in $T_{2}$ seed transformed with the pJP1106 construct (FAD2 target) ranged from 32.9 to $62.7 \%$ in 30 independent transgenic events compared to an average non-transgenic parental level of $12.9 \pm 0.1$. A highly silenced line (plant ID-30, Figure 3) which has a single transgene insertion, determined by segregation ratios $(3: 1)$ of plant selectable marker (PPT) was forwarded to next generation $\left(\mathrm{T}_{3}\right)$. Similarly high levels of the $18: 1^{\Delta 9}$ were observed in $\mathrm{T}_{3}$ seed ranging from 46.0 to $63.8 \%$ with an average of $57.3 \pm 5.0 \%$ in 21 independent transgenic events. In $\mathrm{T}_{4}$ seed also similar high level of $18: 1^{\Delta 9}$ observed from 61 to $65.8 \%$ with an average of 
$63.3 \pm 1.0 \%$ in 23 independent transgenic events. All the means were significantly different from all others $(P<0.01)$. The total PUFA content $\left(18: 2^{\Delta 9,12}+18: 3^{\Delta 9,12,15} 20: 2^{\Delta 11,14}+20: 3^{\Delta 11,14,17}\right)$ in $\mathrm{T}_{2}$ seed ranged from 6.1 to $38 \%$ but in homozygous lines the total PUFA content was further reduced and ranged from 4.3 to 5.7\%. The control Arabidopsis ecotype Columbia has ODP value ranging $0.75-0.79$, meaning that over $75 \%$ of oleic acid produced

Table 2 | Fatty acid profiles of Arabidopsis thaliana $\mathrm{T}_{3}$ homozygous seeds transformed with amiRNAs targeting FAE1 (pJ1109) and FATB (pJ1110), respectively.

\begin{tabular}{|c|c|c|c|}
\hline \multirow[t]{2}{*}{ Fatty acids } & \multirow{2}{*}{$\begin{array}{l}\text { Control } \\
\text { Columbia }\end{array}$} & \multicolumn{2}{|c|}{ Silenced gene } \\
\hline & & FAE1 & FAT-B \\
\hline $16: 0$ & $8.0 \pm 0.3$ & $8.0 \pm 0.2$ & $4.4 \pm 0.5$ \\
\hline $16: 1^{\Delta 9}$ & $0.3 \pm 0.1$ & $0.1 \pm 0.0$ & $0.1 \pm 0.1$ \\
\hline 18:0 & $3.1 \pm 0.2$ & $2.9 \pm 0.3$ & $2.0 \pm 0.1$ \\
\hline $18: 1^{\Delta 9}$ & $12.9 \pm 0.1$ & $24.0 \pm 0.8$ & $16.0 \pm 0.8$ \\
\hline $18: 1^{\Delta 11}$ & $1.9 \pm 0.1$ & $2.2 \pm 0.1$ & $1.6 \pm 0.1$ \\
\hline $18: 2^{\Delta 9,12}$ & $31.4 \pm 0.6$ & $34.9 \pm 1.1$ & $32.5 \pm 0.5$ \\
\hline $18: 3^{\Delta 9,12,15}$ & $19.6 \pm 0.4$ & $25.1 \pm 0.9$ & $23 \pm 0.7$ \\
\hline $20: 0$ & $2.0 \pm 0.0$ & $0.4 \pm 0.1$ & $1.0 \pm 0.1$ \\
\hline $20: 1^{\Delta 11}$ & $15.4 \pm 0.3$ & $1.9 \pm 1.0$ & $15.2 \pm 0.6$ \\
\hline $20: 1^{\Delta 13}$ & $1.7 \pm 0.1$ & $0.4 \pm 0.1$ & $1.5 \pm 0.2$ \\
\hline $20: 2^{\Delta 9,12}$ & $1.8 \pm 0.1$ & $0.1 \pm 0.0$ & $1.4 \pm 0.1$ \\
\hline $22: 0$ & $0.5 \pm 0.1$ & $0.1 \pm 0.1$ & $0.1 \pm 0.0$ \\
\hline $22: 1^{\Delta 13}$ & $1.3 \pm 0.1$ & - & $1.2 \pm 1.2$ \\
\hline $24: 0$ & $0.1 \pm 0.0$ & - & - \\
\hline
\end{tabular}

Values are the means of the entire $T_{3}$ seed of 21 plants (\% of total fatty acids) with the errors reported as SD. Fatty acids directly affected by the gene silencing are shown in bold. in the developing seed is subsequently converted to $18: 2^{\Delta 9,12}$ and $18: 3^{\Delta 9,12,15}$. The fad-2-1 mutant has an ODP value of 0.17 , indicating about a $75 \%$ reduction in $\Delta 12$ desaturation. The ODP values ranged from 0.08 to 0.48 in $\mathrm{T}_{2}$ seed, $0.07-0.32$ in $\mathrm{T}_{3}$ seed, and $0.06-0.08$ in $\mathrm{T}_{4}$ seed in contrast to 0.75 in control Arabidopsis ecotype Columbia (Figure 4A). The drastic reduction in ODP values in transgenic lines clearly indicates the efficient silencing of FAD2 gene using microRNA approach in the present study. Liu et al. (2002) and Maria et al. (2008) demonstrated the reduced levels of ODP are always associated with reduced desaturase mRNA levels in cotton and Arabidopsis using hpRNA and artificial trans-acting siRNA when compared with the control. The degree of FAD2 silencing and the amount of $18: 1^{\Delta 9}$ $(63.3 \pm 1.1 \%)$ observed in this study using amiRNA is higher than the well characterized FAD-2-2 mutant $(59.4 \pm 2.0 \%)$, hairpin $(56.9 \pm 3.6 \%)$, and hairpin-antisense approach $(61.7 \pm 2.0 \%$, Tam and John, 2009). The mean $18: 2^{\Delta 9,12}+18: 3^{\Delta 9,12,15}$ in FAD2 silenced line using amiRNA is $4.7 \pm 0.4 \%$ which is lower than the previously reported FAD-2-2 mutant $(7.5 \pm 1.1 \%)$ and FAD2 silenced line using hairpin-antisense approach $(7.2 \pm 1.4 \%$; Tam and John, 2009) and also lower than the hpFAD-2 silenced line $(8.3 \pm 0.2 \%$; Stoutjesdijk et al., 2002) compared in this study (Table 3).

Stability of inheritance was studied in single highly silenced FAD2 line up to three generations and ODP levels analyzed at each generation (Figure 4A). The wide variation of ODP levels in $\mathrm{T}_{2}$ seeds reflect different silencing efficacy of various transgene insertion events. The ODP of $\mathrm{T}_{3}$ and $\mathrm{T}_{4}$ seeds were significantly different from control Columbia and reflected the stability of the silencing over multiple generations.

\section{FAE1 GENE SILENCING}

Fatty acid elongase is another important gene in fatty acid metabolism regulated in different crops for the altered fatty acid

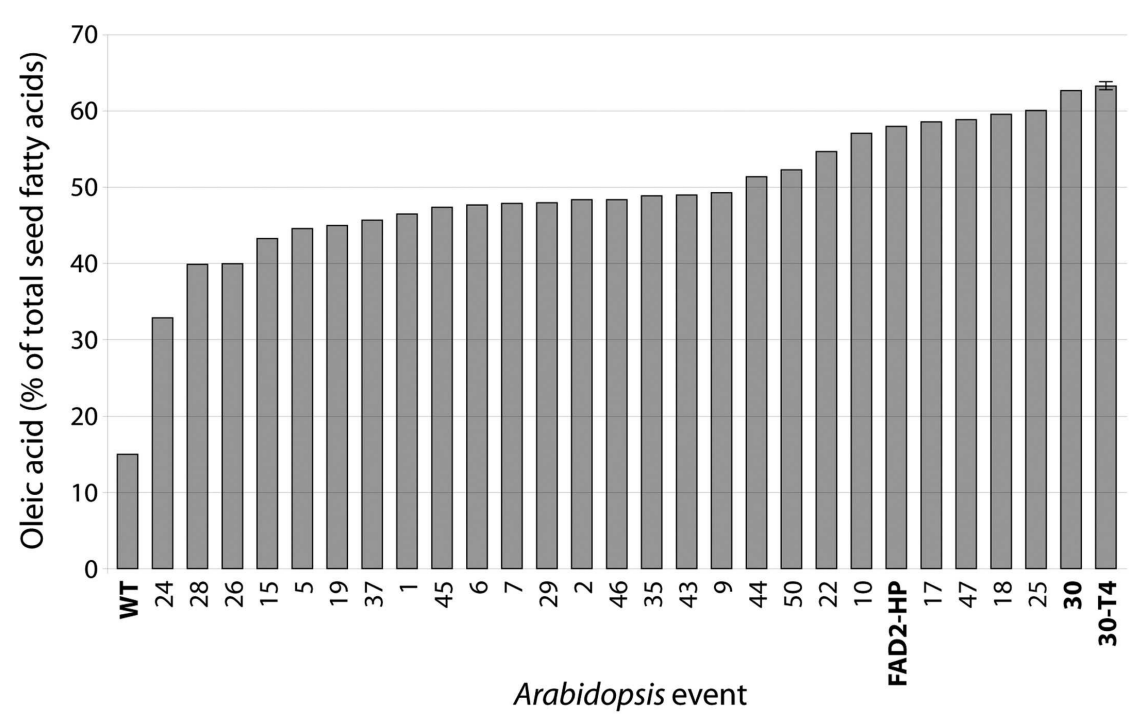

FIGURE 3 | Oleic acid content (\%) of selfed seed of Arabidopsis FAD2 silenced line $\left(T_{2}, n=30\right)$, line 30 forwarded to $T_{3}$ and $T_{4}$ generations. The average $T_{4}(n=23)$ oleic acid content was also shown. Columbia (WT), FAD2 silenced line with RNAi approach (3-1-1) was also shown. 


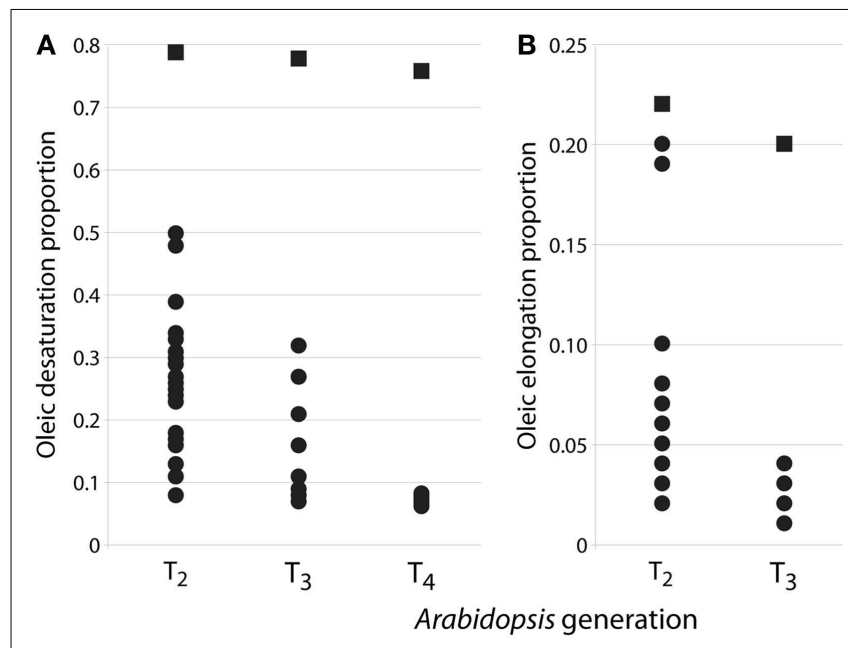

FIGURE 4 | (A) Distribution of oleic desaturation proportion (ODP) values for FAD2 silenced $T_{2}(n=30), T_{3}(n=21)$, and $T_{4}(n=23)$ seed (circles) in comparison with Columbia wildtype seeds (squares) which were grown alongside each generation. (B) Distribution of oleic elongation proportion (OEP) values for FAE1 silenced $T_{2}(n=11), T_{3}(n=12)$, and Columbia control seeds.

composition. The down-regulation of FAE1 using antisense and hpRNA approach resulted in the reduction of erucic acid by 82 and $86 \%$ in Indian mustard respectively (Kanrar et al., 2006; Saheli et al., 2007). In the present study FAE1 silencing was measured by the change in OEP, or the amount of the substrate $18: 1^{\Delta 9}$ that was elongated to $20: 1^{\Delta 11}$. Levels of $20: 1^{\Delta 11}$ in $\mathrm{T}_{2}$ seed transformed with the pJP1109 construct (FAE1 target) ranged from 2.2 to $15.1 \%$ in 12 transgenic events compared to an average in wild type level of $16.5 \% \pm 0.3$. A highly silenced line which has a single transgene insertion, determined by segregation ratios (3:1) of PPT forwarded to next generation $\left(\mathrm{T}_{3}\right)$. Similarly, very low levels of 20:1 ${ }^{\Delta 11}$ was observed in $\mathrm{T}_{3}$ seed ranged from 1.1 to $4.1 \%$. The average $20: 1^{\Delta 11}$ in $\mathrm{T}_{3}$ seed is $1.9 \pm 1.0 \%$, in contrast to $15.0 \%$ in control Columbia seed (Table 2). Thus, an $87 \%$ reduction was observed in the FAE1 activity with this miRNA approach. The fatty acid (18:1 ${ }^{\Delta 9}$ and $\left.20: 1^{\Delta 11}\right)$ averages of control and transformed lines were significantly different $(P<0.01)$. Arabidopsis ecotype Columbia has OEP value ranging 0.20-0.22, indicating that around $20-22 \%$ of $18: 1^{\Delta 9}$ formed during fatty acid synthesis is subsequently elongated via the action of FAE1. In FAE1 silenced lines the OEP values ranged from 0.10 to 0.20 in $\mathrm{T}_{2}$ seed and $0.01-0.04$ in $\mathrm{T}_{3}$ seed in contrast to 0.20 in control Arabidopsis ecotype Columbia (Figure 4B). Thus the activity of the FAE1 is reduced to $1 \%$ from $20 \%$ using the miRNA approach.

\section{FATB GENE SILENCING}

The AtFATB1 thioesterase is involved in the release of fatty acids from ACP, which are subsequently exported from the plastid and incorporated into eukaryotic lipids. In this experiment, FATB silencing was measured simply by comparing the levels of 16:0 in $T_{2}$ and $T_{3}$ seeds. Levels of 16:0 in $T_{2}$ seed transformed with the pJP1110 construct (FATB target) ranged
Table 3 | Fatty acid profiles of Arabidopsis thaliana T $_{4}$ homozygous seeds transformed with single-gene amiRNAs (pJP1106) targeting FAD2.

\begin{tabular}{|c|c|c|c|}
\hline Fatty acids & $\begin{array}{l}\text { Control } \\
\text { Columbia }\end{array}$ & $\begin{array}{l}\text { FAD2 silenced } \\
\text { line }\end{array}$ & $\begin{array}{l}\text { hpRNA silenced } \\
\text { line (3-1-1) }\end{array}$ \\
\hline $14: 0$ & $0.1 \pm 0.0$ & $0.1 \pm 0.0$ & $0.1 \pm 0.0$ \\
\hline $16: 0$ & $6.8 \pm 0.1$ & $4.7 \pm 0.1$ & $4.9 \pm 0.2$ \\
\hline $16: 1^{\Delta 9}$ & $0.3 \pm 0.0$ & $0.3 \pm 0.0$ & $0.40 \pm 0.0$ \\
\hline $16: 3^{\Delta 9,12,15}$ & $0.1 \pm 0.0$ & $0.1 \pm 0.0$ & $0.1 \pm 0.0$ \\
\hline 18:0 & $2.9 \pm 0.0$ & $2.8 \pm 0.1$ & $2.8 \pm 0.1$ \\
\hline $18: 1^{\Delta 9}$ & $18.3 \pm 1.0$ & $63.3 \pm 1.1$ & $58.1 \pm 1.1$ \\
\hline $18: 1^{\Delta 11}$ & $1.7 \pm 0.1$ & $2.1 \pm 0.0$ & $2.1 \pm 0.2$ \\
\hline $18: 2^{\Delta 9,12}$ & $27.5 \pm 0.2$ & $1.7 \pm 0.2$ & $3.3 \pm 0.1$ \\
\hline $18: 3^{\Delta 9,12,15}$ & $17.3 \pm 0.9$ & $3.0 \pm 0.2$ & $5.0 \pm 0.1$ \\
\hline $20: 1^{\Delta 11}$ & $17.6 \pm 0.3$ & $17.5 \pm 0.7$ & $18.5 \pm 1.1$ \\
\hline $20: 1^{\Delta 13}$ & $1.8 \pm 0.1$ & $1.7 \pm 0.1$ & $1.8 \pm 0.1$ \\
\hline $20: 2^{\Delta 11,14}$ & $1.6 \pm 0.0$ & $0.1 \pm 0.0$ & $0.1 \pm 0.0$ \\
\hline $20: 3^{\Delta 11,14,17}$ & $0.4 \pm 0.0$ & $0.0 \pm 0.0$ & $0.1 \pm 0.0$ \\
\hline $20: 0$ & $1.7 \pm 0.1$ & $1.1 \pm 0.2$ & $1.1 \pm 0.7$ \\
\hline $22: 0$ & $0.3 \pm 0.0$ & $0.3 \pm 0.0$ & $0.3 \pm 0.0$ \\
\hline $22: 1^{\Delta 13}$ & $1.5 \pm 0.1$ & $0.8 \pm 0.1$ & $0.9 \pm 0.1$ \\
\hline $24: 0$ & $0.2 \pm 0.0$ & $0.2 \pm 0.0$ & $0.2 \pm 0.0$ \\
\hline $24: 1^{\Delta 15}$ & $0.2 \pm 0.0$ & $0.2 \pm 0.0$ & $0.2 \pm 0.0$ \\
\hline
\end{tabular}

Control Columbia and FAD-2-HP silenced line (Stoutjesdijk et al., 2002) profile were also shown. Values are the means of the entire $T_{4}$ seeds of 23 independent plants (\% of total fatty acids) with the errors reported as SD. Fatty acids directly affected by the gene silencing are shown in bold.

from 4.9 to $6.2 \%$ in 12 transgenic events compared to an average in wild type level of $8.0 \pm 0.3 \%$. A highly silenced line which has a single transgene insertion, determined by segregation ratios (3:1) of PPT was forwarded to next generation $\left(\mathrm{T}_{3}\right)$. Similarly, low levels of 16:0 were observed in $\mathrm{T}_{3}$ seed ranged from 3.4 to $5.0 \%$. The average $16: 0$ in $\mathrm{T}_{3}$ seed was $4.4 \pm 0.5 \%$, in contrast to $8.0 \pm 0.3 \%$ in control Columbia seed (Table 2). Thus, an overall 55\% reduction in 16:0 amount was observed in this study. In the FATB knock-out mutant (Gustavo et al., 2003 ) similar level of reduction $(56 \%)$ in 16:0 was reported in Arabidopsis.

In summary, using the amiRNA approach, three important genes, i.e., FAD2, FAE1, FATB involved in seed oil metabolism were efficiently modulated. The efficiency of FAD2 and FATB silencing is matching with the well characterized mutant alleles. The amiRNA approach uses 21-bp single stranded RNA that target specific sequence offers distinct advantage with reduced risk of cross-silencing over intron-spliced hairpin or other approaches which use longer sequences ( 200). This precise silencing may be particularly useful for manipulating the seed oil composition of economically important oilseed crops.

\section{ACKNOWLEDGMENTS}

We thank Anne Mackenzie, Lijun Tian for their excellent technical assistance. Srinivas Belide gratefully acknowledges the overseas fellowship supported by SNIST and World Bank (Faculty Development Program of TEQIP-I). 


\section{REFERENCES}

Ai, T., Zhang, L., Gao, Z., Zhu, C. X., and Guo, X. (2011). Highly efficient virus resistance mediated by artificial microRNAs that target the suppressor of PVX and PVY in plants. Plant Biol. 13, 304-316.

Alvarez, J. P., Pekker, I., Goldshmidt, A., Blum, E., Amsellem, Z., and Eshed, Y. (2006). Endogenous and synthetic microRNAs stimulate simultaneous, efficient, and localized regulation of multiple targets in diverse species. Plant Cell 18, 1134-1151.

Clough, S. J., and Bent, A. F. (1998). Floral dip: a simplified method for Agrobacterium-mediated transformation of Arabidopsis thaliana. Plant J. 16, 735-743.

Coutu, C., Brandle, J., Brown, D., Brown, K., Miki, B., Simmonds, J., and Hegedus, D. (2007). pORE: a modular binary vector series suited for both monocot and dicot plant transformation. Transgenic Res. 16, 771-781.

Duan, C. G., Wang, C. H., Fang, R. X., and Guo, H. S. (2008). Artificial microRNAs highly accessible to targets confer efficient virus resistance in plants. J. Virol. 82, 11084-11095.

Eamens, A. L., Smith, N. A., Curtin, S. J., Wang, M., and Waterhouse, P. M. (2009). The Arabidopsis thaliana double-stranded RNA binding protein DRB1 directs guide strand selection from microRNA duplexes. RNA 15, 2219-2235.

Gaurav, S., Álvaro Pérez-Quintero, L., Mehedi, H., Tatiana, V. T., and López, C. (2011). Artificial microRNAs (amiRNAs) engineering-On how microRNA-based silencing methods have affected current plant silencing research. Biochem. Biophys. Res. Commun. 406, 315-319.

Gustavo, B., Joaquin, J. S., Michael, R. P., and John, B. O. (2003). Disruption of the FATB gene in Arabidopsis demonstrates an essential role of saturated fatty acids in plant growth. Plant Cell 15, 1020-1033.

Haney, C. H., and Long, S. R. (2010). Plant flotillins are required for infection by nitrogen fixing bacteria. Proc. Natl. Acad. Sci. U.S.A. 107, 478-483.

Herve, V., Vazquez, F., and Crété, P. (2004). The action of ARGONAUTE1 in the miRNA pathway and its regulation by the miRNA pathway are crucial for plant development. Genes Dev. 18, 1187-1197.

Horn, M., and Waterhouse, P. (2010). Rapid match-searching for gene silencing assessment. Bioinformatics 26, 1932-1937.

Jadhav, A., Katavic, V., Marillia, E. F., Michael Giblin, E., Barton, D. L., Kumar, A., Sonntag, C., Babic, V., Keller, W. A., and Taylor, D. C. (2005). Increased levels of erucic acid in Brassica carinata by cosuppression and antisense repression of the endogenous FAD2 gene. Metab. Eng. 7, 215-220.

Kanrar, S., Venkateswari, J., Dureja, P., Kirti, P. B., and Chopra, V. L. (2006). Modification of erucic acid content in Indian mustard (Brassica juncea) by up-regulation and down-regulation of the Brassica juncea fatty acid elongation 1 (BjFAE1) gene. Plant Cell Rep. 25, 148-155.

Khraiwesh, B., Ossowski, S., Weigel, D., and Reski, W. (2008).pdf Frank specific gene silencing by artificial microRNAs in Physcomitrella patens: an alternative to targeted gene knockouts. Plant Physiol. 148, 684-693.

Liu, Q., Surinder, S., and Green, A. (2002). High-stearic and higholeic cottonseed oils produced by hpRNA-mediated posttranscriptional gene silencing. Plant Physiol. 129, 1732-1743.

Maria, G.-N., Aukerman, M. J., Hajime, S., Scott, V. T., and Robert, W. W. (2008). Artificial trans-acting siRNAs confer consistent and effective gene silencing. Plant Physiol. 147, 543-551.

Miquel, M., and Browse, J. (1992). Arabidopsis mutants deficient in polyunsaturated fatty acid synthesis. Biochemical and genetic characterization of a plant oleoylphosphatidylcholine desaturase. J. Biol. Chem. 267, 1502-1509.

Molnar, A., Bassett, A., Thuenemann, E., Schwach, F., Karkare, S., Ossowski, S., Weigel, D., and Baulcombe, D. (2009). Highly specific gene silencing by artificial microRNAs in the unicellular alga Chlamydomonas reinhardtii. Plant J. 58, 165-174.

Murashige, T., and Skoog, F. (1962). A revised medium for rapid growth and bioassays with tobacco tissue cultures. Physiol. Plant. 15, 473-497.

Napier, J. A. (2007). The production of unusual fatty acids in transgenic plants. Annu. Rev. Plant Biol. 58, 95-319.

Niu, Q. W., Lin, S. S., Reyes, J. L., Chen, K. C., Wu, H. W., Yeh, S. D., and Nam-Hai, C. (2006). Expression of artificial microRNAs in transgenic Arabidopsis thaliana confers virus resistance. Nat. Biotechnol. 24, 1420-1428.

Okuley, J., Lightner, J., Feldmann, K., Yadav, N., Lark, E., and Browse, J. (1994). Arabidopsis FAD2 gene encodes the enzyme that is essential for polyunsaturated lipid synthesis. Plant Cell 6, 147-158.

Pidkowich, M. S., Nguyen, H. T., Heilmann, I., Ischebeck, T., and Shanklin, J. (2007). Modulating seed betaketoacyl-acyl carrier protein synthase II level converts the composition of a temperate seed oil to that of a palm-like tropical oil. Proc. Natl. Acad. Sci. U.S.A. 104, 4742-4747.

Qu, J., Ye, J., and Fang, R. (2007). Artificial microRNA-mediated virus resistance in plants. J. Virol. 81, 6690-6699.

Saheli, S., Jyoti Jha, K., Mrinal, K. M., Asitava, B., Ujjal, K. M., and Soumitra, K. S. (2007). Metabolic engineering of fatty acid biosynthesis in Indian mustard(Brassica juncea) improves nutritional quality of seed oil. Plant Biotechnol. Rep. 1, 185-197.

Schwab, R., Ossowski, S., Riester, M., Warthmann, N., and Weigel, D. (2006). Highly specific gene silencing by artificial microRNAs in Arabidopsis. Plant Cell 18, 1121-1133.

Sellwood, C., Slabas, A. R., and Rawsthorne, S. (2000). Effects of manipulating expression of acetyl-CoA carboxylase I in Brassica napus L. embryos. Biochem. Soc. Trans. 28, 598-600.

Somerville, C. R., and Browse, J. A. (1991). Plant lipids: metabolism, mutants, and membranes. Science 252, 80-87.

Stoutjesdijk, P. A., Surinder, S. P., Liu, Q., Hurlstone, C. J., Waterhouse, P. A., and Green, A. G. (2002). hpRNAmediated targeting of the Arabidopsis FAD2 gene gives highly efficient and stable silencing. Plant Physiol. 129, 1723-1731.

Surinder, S., Green, A., Stoutjesdijk, P., and Liu, Q. (2000). Inverted-repeat DNA: a new gene-silencing tool for seed lipid modification. Biochem. Soc. Trans. 28, 925-927.

Tam, N., and John, S. (2009). Altering Arabidopsis oilseed composition by a combined antisensehairpin RNAi gene suppression approach. J. Am. Oil Chem. Soc. 86, 41-49.

Tang, G., Galili, G., and Zhuang, X. (2007). RNAi, microRNA: breakthrough technologies for the improvement of plant nutritional value and metabolic engineering. Metabolomics 3, 357-369.

Toppino, L., Kooiker, M., Lindner, M., Dreni, L., and Rotino, G. L., Kater, M. M. (2011). Reversible male sterility in eggplant (Solanum melongena L.) by artificial microRNA mediated silencing of general transcription factor genes. Plant Biotechnol. J. 9, 684-692.

Warthmann, N., Chen, H., Ossowski, S., Weigel, D., and Herve, P. (2008). Highly specific gene silencing by artificial miRNAs in rice. PLoS ONE 3, e1829. doi:10.1371/journal.pone.0001829

Zar, J. H. (2010). Biostatistical Analysis, 5th Edn. Upper Saddle River, NJ: Prentice-Hall.

Zhang, X., Li, H., Zhang, J., Zhang C., Gong, P., Ziaf, K., Xiao, F., and Ye, Z. (2010). Expression of artificial microRNAs in tomato confers efficient and stable virus resistance in a cell-autonomous manner. Transgenic Res. 3, 1-13.

Zhou, X., Singh, S., Liu, Q., and Green, A. (2006). Combined transgenic expression of $\delta 12$-desaturase and 812 -epoxygenase in high linoleic acid seeds leads to increased accumulation of vernolic acid. Funct. Plant Biol. 33, 585-592.

Conflict of Interest Statement: The authors declare that the research was conducted in the absence of any commercial or financial relationships that could be construed as a potential conflict of interest.

Received: 27 April 2012; paper pending published: 21 May 2012; accepted: 07 July 2012; published online: 31 July 2012.

Citation: Belide S, Petrie JR, Shrestha $P$ and Singh SP (2012) Modification of seed oil composition in Arabidopsis by artificial microRNA-mediated gene silencing. Front. Plant Sci. 3:168. doi: 10.3389/fpls.2012.00168

This article was submitted to Frontiers in Plant Biotechnology, a specialty of Frontiers in Plant Science.

Copyright $(\odot 2012$ Belide, Petrie, Shrestha and Singh. This is an open-access article distributed under the terms of the Creative Commons Attribution License, which permits use, distribution and reproduction in other forums, provided the original authors and source are credited and subject to any copyright notices concerning any third-party graphics etc. 